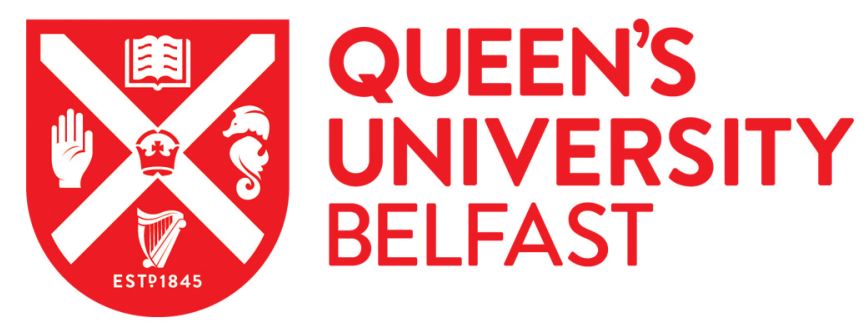

\title{
Expiratory airflow in late adolescence and early adulthood in individuals born very preterm or with very low birthweight compared with controls born at term or with normal birthweight: a meta-analysis of individual participant data
}

Doyle, L. W., Andersson, S., Bush, A., LY Cheong, J., Clemm, H., Evensen , K. A. I., Gough, A., Halvorson, T., Hovi, P., Kajantie , E., Lee, K. J., McGarvey, L., Narang , I., Näsänen-Gilmore, P., Steinshamn, S., Vollsaeter, M., \& Vrijlandt, E. JLE. (2019). Expiratory airflow in late adolescence and early adulthood in individuals born very preterm or with very low birthweight compared with controls born at term or with normal birthweight: a metaanalysis of individual participant data. The Lancet Respiratory Medicine, 7(8), 677. https://doi.org/10.1016/S2213-2600(18)30530-7

Published in:

The Lancet Respiratory Medicine

Document Version:

Peer reviewed version

Queen's University Belfast - Research Portal:

Link to publication record in Queen's University Belfast Research Portal

\section{Publisher rights}

Copyright 2019 Elsevier

This manuscript is distributed under a Creative Commons Attribution-NonCommercial-NoDerivs License

(https://creativecommons.org/licenses/by-nc-nd/4.0/), which permits distribution and reproduction for non-commercial purposes, provided the author and source are cited

\section{General rights}

Copyright for the publications made accessible via the Queen's University Belfast Research Portal is retained by the author(s) and / or other copyright owners and it is a condition of accessing these publications that users recognise and abide by the legal requirements associated with these rights.

\section{Take down policy}

The Research Portal is Queen's institutional repository that provides access to Queen's research output. Every effort has been made to ensure that content in the Research Portal does not infringe any person's rights, or applicable UK laws. If you discover content in the Research Portal that you believe breaches copyright or violates any law, please contact openaccess@qub.ac.uk. 
Expiratory airflow in late adolescence/early adulthood in survivors born very preterm or very low birthweight compared with controls - an individual participant data meta-analysis

${ }^{1}$ Lex W Doyle MD, ${ }^{2}$ Sture Andersson PhD, ${ }^{3}$ Andy Bush MD, ${ }^{1}$ Jeanie LY Cheong, MD, ${ }^{4}$ Hege Clemm PhD, ${ }^{5}$ Kari Anne I Evensen $\mathrm{PhD},{ }^{6}$ Aisling Gough $\mathrm{PhD},{ }^{4}$ Thomas Halvorsen $\mathrm{PhD}$, ${ }^{2,7}$ Petteri Hovi PhD, ${ }^{2,7,8}$ Eero Kajantie PhD, ${ }^{9}$ Katherine J Lee PhD, ${ }^{6,10}$ Lorcan McGarvey MD,

${ }^{11}$ Indra Narang MD, ${ }^{2}$ Pieta Näsänen-Gilmore PhD, ${ }^{12}$ Sigurd Steinshamn PhD, ${ }^{4}$ Maria Vollsaeter $\mathrm{PhD},{ }^{13}$ Elianne JLE Vrijlandt $\mathrm{PhD}$.

${ }^{1}$ Department of Obstetrics and Gynaecology, The Royal Women's Hospital, and the Department of Paediatrics, University of Melbourne, and Murdoch Children's Research Institute, Melbourne, Australia; ${ }^{2}$ Children's Hospital, Helsinki University Hospital and University of Helsinki, Helsinki, Finland, ${ }^{3}$ Imperial College and Royal Brompton Hospital, London, UK; ${ }^{4}$ Pediatric Department, Haukeland University Hospital, Bergen, Department of Clinical Science, University of Bergen, Norway; ${ }^{5}$ Department of Clinical and Molecular Medicine, and Department of Public Health and Nursing, Norwegian University of Science and Technology, Trondheim, Norway; ${ }^{6}$ Centre of Excellence for Public Health, School of Medicine, Dentistry and Biomedical Sciences, Queen's University, Belfast, Northern Ireland; ${ }^{7}$ National Institute for Health and Welfare, Department of Public Health Solutions, Public Health Promotion Unit, Helsinki and Oulu, Finland; ${ }^{8}$ PEDEGO Research Unit, MRC Oulu, Oulu University Hospital and University of Oulu, Oulu, Finland ${ }^{9}$ Clinical Epidemiology and Biostatistics, Murdoch Children's Research Institute, Melbourne, and Department of Paediatrics, University of Melbourne, Australia; ${ }^{10}$ Centre for Experimental Medicine, School of Medicine, Dentistry and Biomedical Sciences, Queen's University, Belfast, Northern Ireland; ${ }^{11}$ Division of Respiratory Medicine, Hospital for Sick Children, University of Toronto, Toronto, Canada; ${ }^{12}$ Department of Circulation and Medical Imaging, Norwegian University of Science and Technology, Trondheim, Norway, and Clinic of Thoracic and Occupational Medicine, St. Olavs Hospital, Trondheim University Hospital, Trondheim, Norway; ${ }^{13}$ Department of Pediatric Pulmonology, Beatrix Children's Hospital, University Medical Center Groningen, University of Groningen, The Netherlands.

Correspondence: Lex W Doyle MD, Department of Obstetrics and Gynaecology, The Royal Women's Hospital, 20 Flemington Rd, Parkville, 3052, Australia. 
Telephone (61 3) 8345 3716; FAX (61 3) 8345 3702;

Email: 1wd@unimelb.edu.au

Word count: 3580

\section{Research in context}

\section{Evidence before this study}

Airflow capacity peaks in the early 20 s in healthy people, then slowly declines with age. We identified relevant studies through the Adults born Preterm International Collaboration (APIC; www.apic-preterm.org), and from searching PubMed and Embase for studies of lung function in late adolescence or early adulthood in humans using terms "respiratory function OR lung function OR spirometry" combined with "preterm OR low birth weight" (searched May, 2016). Individual cohort studies of airflow capacity in late adolescence or early adulthood of survivors born very preterm (VP; $<32$ weeks' gestational age) or very low birthweight (VLBW; $<1500 \mathrm{~g}$ ) have mainly reported reductions in airflow, particularly in those who had bronchopulmonary dysplasia (BPD) in the newborn period, but there is variation in the size of the reductions. Moreover, airflow trajectory after the early 20 s is unclear.

\section{Added value of this study}

VP/VLBW survivors are not reaching the normal peak of airway capacity in their early $20 \mathrm{~s}$. The reductions in airflow capacity in VP/VLBW survivors in early adulthood are substantial, with more than a 4 -fold increase in the numbers with values in worrying clinical ranges compared with term-born or normal birthweight survivors. Moreover, there is no evidence to suggest that the rate of change in airway capacity after the early 20 s is better in VP/VLBW survivors compared with controls, and it may even be worse. VP/VLBW survivors who had BPD in the newborn period have even worse airflow capacity that those who did not have BPD.

\section{Implications of all available evidence}

Adult physicians, whether they be in general practice or are specialists, need to be aware that more infants born VP/VLBW are now surviving into adulthood, and many will present with 
symptoms of airflow obstruction. Adult physicians should know the gestational age and birth weight of their patients with respiratory disease and be aware that patients who were born VP/VLBW, particularly those who had BPD, are at high risk of chronic obstructive pulmonary disease. 


\begin{abstract}
Background: Maximal expiratory airflow peaks in the early 20s, then gradually declines with age. The pattern of airflow through adulthood for individuals born very preterm (VP; $<32$ weeks' gestation) or very low birthweight (VLBW; <1501 g) is unknown.
\end{abstract}

Objectives: To compare maximal expiratory airflow in late adolescence/early adulthood in survivors born VP/VLBW with normal birthweight ( $>2499 \mathrm{~g}$ ) or term-born controls, and determine perinatal and demographic associations with airflow in VP/VLBW survivors.

Data sources: Cohort studies, mostly from the pre-surfactant era

Study eligibility: Survivors born VP/VLBW and controls beyond 16.0 years of age

Study appraisal and synthesis methods: Studies were identified through the Adults born Preterm International Collaboration and searching PubMed and Embase. Individual participant data on expiratory flow variables ( forced expired volume in 1 second $\left(\mathrm{FEV}_{1}\right)$, forced vital capacity (FVC), $\mathrm{FEV}_{1} / \mathrm{FVC}$, and flow between $25 \%-75 \%$ of the vital capacity $\left(\mathrm{FEF}_{25-75 \%}\right)$ ) were converted to z-scores and analysed using generalised linear mixed models in a one-step approach. Results: There were 935 VP/VLBW and 722 controls from eleven individual cohorts; the mean age at testing was 21 (range 16-33) years. Controls had mean z-scores close to the expected values of zero, but VP/VLBW survivors were substantially lower by approximately $-0.75 \mathrm{SD}$ (upper $\mathrm{CI}<-0.60 \mathrm{SD}$ ) for $\mathrm{zFEV}_{1}, \mathrm{zFEV}_{1} / \mathrm{FVC}$, and $\mathrm{FFEF}_{25-75 .}$. Moreover, approximately onequarter of VP/VLBW participants had values less than the $5^{\text {th }}$ centile for most variables, more than four-fold higher than controls. The trajectory of airflow was no better in the VP/VLBW group than controls. Among VP/VLBW survivors, better airflow was associated with antenatal corticosteroids, female sex, and no history of bronchopulmonary dysplasia; zFVC was higher in smokers.

Conclusions: VP/VLBW survivors seem not to be reaching their full airway growth potential in early adulthood, suggesting an increased risk of chronic obstructive pulmonary disease in later adulthood.

Funding: National Health and Medical Research Council; University of Bergen, Western Norway Regional Authority; National Institute for Health Research, UK; Stichting Astmabestrijding; St. Olav's Hospital's Research Fund; Academy of Finland; European Commission; NICHD; Victorian Government's Operational Infrastructure Support Program. 


\section{Introduction}

Maximal expiratory airflow, which reflects airway growth, increases throughout childhood, peaking in the early $20 \mathrm{~s}$, and then slowly declines with age, with only small differences in the pattern of change with age between males and females. ${ }^{1}$ In elderly people with normal lung function the gradual decline in airflow with age is not a concern because they are likely to die from other causes before airflow declines to a point where individuals become symptomatic. However, an excessive rate of decline in airflow, such as may occur with tobacco smoking, is concerning, and leads to higher rates of chronic obstructive pulmonary disease (COPD) in adulthood. ${ }^{2}$ Similarly, individuals who do not reach their expected peak airflow might also become symptomatic earlier in adulthood than expected.

The development of prenatal and neonatal care in recent decades has brought about dramatic improvements in the prognosis for infants born very preterm (VP; $<32$ weeks' gestation) or with very low birthweight (VLBW; $<1501 \mathrm{~g}$ ), who constitute $1-2 \%$ of all births worldwide. ${ }^{3}$ Many of these "new survivors" have reached adulthood: the number of VP/VLBW survivors born in the 1970s and 1980s is estimated as over half a million in the USA alone. ${ }^{4,5}$ Therefore, questions related to their health are increasingly relevant. VP/VLBW survivors have more airway obstruction in childhood than those born of normal birthweight NBW; (>2499 g), a difference that persists into early adulthood. ${ }^{6-14}$ Those who had bronchopulmonary dysplasia (BPD) in the newborn period have even more airway obstruction than do VP/VLBW survivors without BPD. ${ }^{6-8,10,11,13,14}$ Apart from BPD, the relationships of airflow in VP/VLBW survivors in early adulthood with other perinatal events, such as antenatal corticosteroids, gestational age, fetal growth, or sex, or with tobacco smoking are unclear, partly because existing studies are based on single cohorts, with limited power. Moreover, the rate of decline in airflow with age beyond the peak of maximal airflow capacity in VP/VLBW survivors in adulthood is unknown. In this individual patient data (IPD) meta-analysis we aimed to compare airflow in late adolescence and early adulthood in survivors born VP/VLBW mostly in the pre-surfactant era with NBW or term-born controls, including the trajectory of airflow after the expected peak in the early 20 s, and to identify perinatal and demographic risk and protective associations with airflow among preterm survivors. It was hypothesized that VP/VLBW survivors would have worse airflow than controls, and that, within the VP/VLBW group, those who had BPD and those who were smokers would have even worse airflow.

\section{Methods}


Through the Adults born Preterm International Collaboration (APIC; www.apic-preterm.org), we identified studies potentially suitable for inclusion in an IPD meta-analysis. APIC was formed in 2011 and comprises research groups from around the world with health data on cohorts of participants born VP/VLBW who had been followed into late adolescence or early adulthood. ${ }^{15}$ We also searched PubMed and Embase for studies of lung function in late adolescence or early adulthood in humans using terms "respiratory function OR lung function OR spirometry" combined with "preterm OR low birth weight" (searched May, 2016).

\section{Inclusion Criteria for Studies}

Inclusion criteria comprised the following: cohort studies of survivors born VP/VLBW, where NBW or term-born controls were also studied, and where the age of participants when measuring expiratory flows was 16 years or older. We did not include highly-selected cohorts, such as just those with BPD, or cohort studies where all birthweights or gestational ages were studied, but few were born VP/VLBW, or where it was impossible to determine whether those studied represented the sample of all possible survivors from either the hospitals or geographical regions concerned. Methods and criteria for selection of controls varied from study to study (Supplementary Table 1).

\section{Data Requested}

Perinatal data, including year of birth, antenatal corticosteroid therapy, gestational age, birthweight, sex, and bronchopulmonary dysplasia (BPD) were requested from each study. Data on maternal smoking during pregnancy were missing for approximately one-third of the participants $(33 \% ; 540 / 1657)$, so it was only considered as a potential confounder in secondary analyses comparing differences in flow rates between VP/VLBW and control groups. Birthweight z-scores were computed for age and sex, relative to the British Growth Reference. ${ }^{16}$ BPD definition varied between studies, from either oxygen dependency at 28 days, with or without chest X-ray changes consistent with Northway's classification, ${ }^{17}$ to oxygen dependency at 36 weeks' postmenstrual age. ${ }^{18}$ At the time of lung function assessment, a history of current tobacco smoking was obtained.

\section{Expiratory Flows}

In all cohorts, forced expiratory flow was measured using spirometry according to the American Thoracic Society and European Respiratory Society guidelines, ${ }^{19}$ or equivalent guidelines at the time that the cohorts were studied. The following values were obtained; forced expired volume in 
1 second $\left(\mathrm{FEV}_{1}\right)$, forced vital capacity $(\mathrm{FVC})$, and the ratio of the two $\left(\mathrm{FEV}_{1} / \mathrm{FVC}\right)$, and the forced expiratory flow at $25 \%-75 \%$ of $\mathrm{FVC}\left(\mathrm{FEF}_{25 \%-75 \%}\right)$. Two studies did not measure $\mathrm{FEF}_{25 \%-}$ $75 \%{ }^{10,12}$ We did not collect data on bronchodilator responses because they were not measured in all studies, and in some studies that did, they were measured only on subsets of participants with low expiratory flows..

Expiratory flows were converted to z-scores for age, height, sex and ethnicity, relative to the Global Lung Initiative 2012 reference values. ${ }^{20}$ The proportions with clinically important values for airflow $<5^{\text {th }}$ percentile were computed.

\section{Governance}

Participants in each cohort had been recruited after providing informed consent and each study had been approved by the appropriate Institutional Review Boards (IRBs). When required, investigators obtained separate permission from their IRBs to submit data for the IPD metaanalysis. Written data transfer agreements were obtained between the Murdoch Children's Research Institute, where the data were pooled and analysed, and the other centres which provided data. Non-identifiable data were then transferred for analysis.

\section{Data Analysis}

Data were analysed using Stata 15.1. ${ }^{21}$ Analyses were conducted using generalised linear mixed models in a one-step approach, with a random effect for cohorts to account for the lack of independence of the data within cohorts, and a second random effect to account for more than one measurement taken at two different ages in two cohorts. In some analyses the models would not converge with two random effects, or the second random effect for more than one measurement was not required, so the second random effect was dropped. Expiratory flow data from VP/VLBW participants were compared with controls by the inclusion of a fixed effect for group. To establish the trajectory of decline after the expected peak of maximal airway capacity in VP/VLBW survivors, the relationships of expiratory flows with age at testing were repeated with the analyses limited to those participants with ages $>21$ years. Also, in the two studies where the same participants were tested at two ages (approximately 18 and 25 years, respectively), the differences in airway capacity between the ages were analysed using mixed models with a random effect for the two different sites, with and without adjusting for the baseline expiratory flow values for each variable. Within the VP/VLBW group univariable relationships of expiratory flows with antenatal corticosteroids, gestational age, birthweight z-score, sex, BPD, 
smoking, year of birth, and age at testing were explored, and then all variables were entered in multivariable analyses to determine the independent associations of these variables with expiratory flows.

The funding sources had no role in the study design, collection, analysis or interpretation of the data, or the writing of the report. LD had access to the raw data. The corresponding author had full access to all of the data and the final responsibility to submit for publication.

\section{Results}

Eleven cohorts met the inclusion criteria, as shown in Table 1, listed in chronological order by year of birth. ${ }^{6-14,22,23}$ In two cohorts, measurements were obtained twice from some participants; at approximately 18 years of age, ${ }^{11,22,23}$ and again at approximately 25 years of age. ${ }^{6,11,23}$ One site recruited cohorts from two different eras. ${ }^{11}$ A repeat literature search in January 2018 did not identify any additional potentially eligible cohorts. Across the 11 cohorts there were 935 preterm and 722 controls with airflow data available for analysis. The studies were from six different high-income countries, approximately one-half were regional studies, years of birth ranged from 1977 to 1993, and the age when studied ranged from 16 to 33 years. Most of the 1657 participants in both birth groups were Caucasian (96.1\%; $\mathrm{n}=1592)$, followed by South-East Asian $(1.8 \% ; n=30)$, other/mixed $(1.5 \% ; n=25)$, and black $(0.5 \% ; n=9)$; only $0.1 \%(n=1)$ were NorthEast Asian.

Among the VP/VLBW participants, rates of antenatal corticosteroid therapy ranged from $6 \%$ to $71 \%$ across the cohorts, mean gestational ages and birthweights fell over time, just under $50 \%$ were male, and surfactant treatment was uncommon until births in the 1990s (Table 2). Rates of smoking ranged from $3 \%$ to $42 \%$.

\section{VP/VLBW compared with controls}

Controls had mean z-scores for expiratory flows close to the expected values of zero, but VP/VLBW survivors had substantially lower mean values for all expiratory flows of

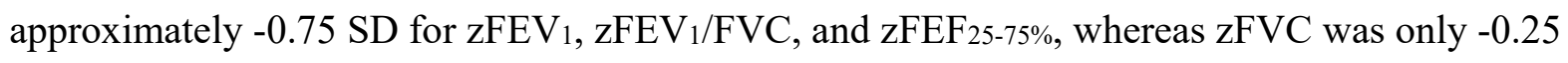
SD lower (Table 3). Maternal smoking in pregnancy was associated with reductions in all airflows except zFVC; adding maternal smoking to the model changed the difference between VP/VLBW and control groups by less than $\pm 0.03 \mathrm{SD}$ and altered no conclusions. 
Approximately one-quarter of VP/VLBW participants had values less than the $5^{\text {th }}$ centile for most flow variables, and proportions for all variables were substantially higher than in controls, where the proportions less than the $5^{\text {th }}$ centile were close to the expected value of $5 \%$ (Table 3 ). There was little heterogeneity between the studies, as assessed by the $\mathrm{I}^{2}$ statistic for any of the expiratory flow variables; $\mathrm{zFEV}_{1} 2.0 \%$, zFVC $0.4 \%, \mathrm{zFEV}_{1} / \mathrm{FVC}^{0.2 \%}$ and $\mathrm{zFEF}_{25-75 \%} 5.7 \%$. Forest plots for each variable showing results for individual studies and the overall summaries are shown in Supplementary Figure 1.

Most cohorts were selected by birthweight only and hence most of the VP/VLBW group were VLBW (99\%; 927/935). However, most were also VP (90\%; 841/935). There was little difference in summary values for expiratory flow variables regardless of the way the VP/VLBW cohort was categorised (Supplementary Table 2).

There were 669 participants assessed at ages $>21.0$ years; 360 were born VP/VLBW and 309 were controls. Among this group of older participants, there was evidence that the rate of change with age in z-scores was lower in the VP/VLBW participants compared with controls for $\mathrm{zFEV}_{1}$ (coefficient $-0.06,95 \%$ CI $-0.10,-0.01$; interaction $\mathrm{p}=0.025$; ) and zFVC (coefficient $-0.06,95 \%$ CI $-0.10,-0.02$; interaction $\mathrm{p}=0.001$ ), but not for $\mathrm{zFEV} / \mathrm{FVC}$ (interaction $\mathrm{p}=0.98$ ) or $\mathrm{zFEF}_{25-75 \%}$ (interaction $\mathrm{p}=0.16$ ). Although the interaction term was significant for $\mathrm{zFEV}_{1}$, there was little evidence for any associations with age at testing in either subgroup alone (VP/VLBW coefficient $0.00,95 \%$ CI $-0.03,0.03 ; p=0.93$; controls coefficient $0.02,95 \%$ CI $-0.01,0.05 ; p=0.14$ ). In contrast, for zFVC the evidence for a positive association with age at testing was strong among the controls (coefficient $0.05,95 \%$ CI 0.03, 0.08; $<<0.0001$ ), but there was little evidence for any association within the VP/VLBW group $(\mathrm{p}=0.84)$.

There were $117 \mathrm{VP} / \mathrm{VLBW}$ participants and 53 controls who had airflow measured on two occasions; at 18 years and 25 years of age. $\mathrm{zFEV}_{1}$ increased between 18 and 25 years in both groups by a similar amount (Table 4). zFVC increased between 18 and 25 years in both groups, but less so in the VP/VLBW group, a difference which was sustained after adjusting for the baseline value of zFVC. zFEV $1 / F V C$ decreased between the two ages more in the controls, but the differences between the groups were not substantial, before or after adjustment for the baseline value of $\mathrm{zFEV}_{1} / \mathrm{FVC}$.

\section{Perinatal and demographic associations within the VP/VLBW group}


There was evidence that gestational age was positively associated with all flow rates, and that zFVC was higher with year of birth and age of testing, but the evidence disappeared in the multivariable analyses (Figure 1). There was strong evidence on both univariable and multivariable analysis that $\mathrm{zFEV}_{1}$ was higher with antenatal corticosteroids, but lower in males and in those who had BPD, that $\mathrm{zFVC}$ was higher with antenatal corticosteroids and in smokers, but lower in those who had BPD, and that both $\mathrm{zFEV}_{1} / \mathrm{FVC}$ and $\mathrm{zFEF}_{25-75 \%}$ were lower in males and in those who had BPD.

\section{Discussion}

The major findings of this IPD meta-analysis are that late adolescents/young adults born VP/VLBW had substantially lower airflow rates and they were over four-fold more likely to have reduced values that were clinically important than did controls. Among VP/VLBW survivors, there were strong independent negative relationships of airflow with male sex and BPD, and positive relationships with antenatal corticosteroids. An unexpected finding was that $\mathrm{zFVC}$ was higher in smokers. As the range of ages of assessment included the age when peak lung growth normally occurs in the early 20 s it is apparent that infants born VP/VLBW are not achieving their full airway growth potential, since they have substantially lower z-scores for all expiratory flows. In analyses restricted to those over 21 years of age, the rate of change of airflow with age was less in VP/VLBW participants compared with controls, suggesting that the rate of decline in later adulthood in VP/VLBW survivors might be higher than in controls. Even if the maximal expiratory airflow declines at a normal rate with age in VP/VLBW adults, proportionally more are destined to develop COPD later in life than controls; $26 \%$ of people in a normal population will develop COPD if they fail to reach a normal airflow plateau in early adulthood. ${ }^{24}$ If their maximal expiratory airflow declines at a faster rate, even more adults born VP/VLBW will develop COPD; however, it is too soon to know for certain what the rate of decline might be throughout adulthood for those born VP/VLBW.

The overall results are consistent with data from the individual studies of young adults who were born VP/VLBW compared with controls, and within VP/VLBW cohorts comparing those who did and did not have BPD. ${ }^{6-14}$ What the IPD has allowed is more precise estimates of effect sizes, assessment of the rate of decline in airflow capacity beyond the early 20s, and an investigation of other independent associations of flow rates with variables that is not possible within a typical 
meta-analysis of cohort studies. We can confirm that the differences between VP/VLBW survivors and controls are large, and that more than four-fold have values in worrying clinical ranges $\left(<5^{\text {th }}\right.$ centile) compared with controls. Moreover, survivors born VP/VLBW who had BPD have even worse expiratory flow rates. The associations with sex and antenatal corticosteroids have not been previously reported in cohorts of survivors born VP/VLBW in adulthood, although one study combining 10-year-olds and 17-year-olds did report improved airflow with antenatal corticosteroid exposure. ${ }^{25}$

To the best of our knowledge we have included all cohort studies of VP/VLBW participants who met our eligibility criteria. Four cohort studies were not included. Northway et $\mathrm{al}^{26}$ studied 26 highly-selected individuals with BPD, 26 preterm individuals without BPD and 53 term controls, born in the early era of assisted ventilation from 1964 to 1973 . Because the mean birthweight was $>1800 \mathrm{~g}$ and the mean gestational age was $>33$ weeks in the preterm groups, few individuals would have been VP/VLBW. This study was also excluded because their results are unlikely to be typical of the era when assisted ventilation was more routine, from the mid-1970s onwards. Wong et $\mathrm{al}^{27}$ included only 21/133 survivors with BPD from one hospital born between 19801987 , and there were no non-BPD preterm children or controls. In the study of Landry et $\mathrm{al}^{28}$ participants were recruited from births in Quebec between 1987-1993 into one of four groups with sample sizes of approximately 30 each based on gestational age and respiratory morbidity criteria. However, it was not possible to determine how many infants might have been eligible from the province of Quebec within each group over the time of birth of the participants. Moschino et $\mathrm{al}^{29}$ assessed lung function from childhood to 24 years of age in 17 participants who had BPD and who were born over a 3-year period in 1991-1993; there were no non-BPD participants or term-born controls; hence the study was excluded. We also did not include studies $^{30,31}$ where survivors of all birthweights and gestational ages were studied because so few would have been VP/VLBW relative to the number of potential controls.

The association of higher values for $\mathrm{zFVC}$, but no other expiratory flows, in smokers than nonsmokers, in both VP/VLBW participants and controls, was unexpected. Others have, however, reported that adolescents and young adults who smoke have higher FVC than non-smokers. ${ }^{32}$ Why zFVC might be higher in smokers is unclear, but, whatever the explanation, the finding needs replication in survivors born VP/VLBW. More importantly, participants in the current 
studies should have airflow measured in later life to determine longer-term effects of smoking on expiratory flows in those born VP/VLBW.

In a follow-up study of 5718 men born in Hertfordshire, England during 1911-30, lower birthweight, and presumably increasing prematurity, was associated with higher death rates from COPD, and worse respiratory function at 59-70 years of age. ${ }^{33}$ In another study of 2984 survivors born in Sweden from 1925 to 1949 with a birthweight $<2100$ g or gestational age $<35$ weeks, COPD was more common with either diminishing birthweight or earlier gestational age. ${ }^{34}$ Current studies of expiratory airflow in preterm survivors of modern perinatal/neonatal intensive care have only been in participants aged up to their early $30 \mathrm{~s}$, which is too early to detect high rates of COPD, or of death caused by COPD.

Several recent studies have reported that trajectories of expiratory flows track from childhood into adulthood, in one report into the $50 \mathrm{~s},{ }^{35}$ and in the other report into the $20 \mathrm{~s} .{ }^{36}$ However, these studies would have had few VP/VLBW participants and hence tracking of expiratory flows of VP/VLBW survivors from childhood into adulthood remains to be determined.

There are a number of limitations of the current study. The data are largely derived from cohorts born before exogenous surfactant was available from the early 1990s; however, the data are relevant to the thousands of survivors born VP/VLBW before the early 1990s who are now adults. The rate of change in airflow capacity in adulthood among survivors born VP/VLBW in the surfactant era remains to be established. The protocols for each study varied in inclusion criteria, ages at assessment, definitions of BPD, and respiratory function tests performed, resulting in heterogeneous cohorts being studied. The NICHD definition of BPD was reported in $2001,{ }^{18}$ which was after the birth of all of the participants in the current study. The data required to define BPD as per the NICHD definition were not available for all cohorts and hence it could not be determined retrospectively. Variation between studies can be avoided by agreeing on common protocols and performing prospective individual participant meta-analyses, which should be the way forward in future studies of VP/VLBW survivors. However, variation between the studies is also a strength because the reductions in airflow between VP/VLBW and control cohorts are consistent across the various studies, and hence the conclusions are widely applicable to VP/VLBW survivors from the same era who have not been studied. We could not analyse data that were not collected consistently across all studies, such as bronchodilator responses to determine the reversibility of airway obstruction, passive smoke exposure in childhood, pack- 
years of active smoking, or respiratory illnesses through childhood. We also had substantial missing data on maternal smoking; adding it as a covariate had little effect on any conclusions concerning differences between VP/VLBW and control groups. We did not add asthma as a covariate to any group differences between VP/VLBW and control groups as asthma might lie along the casual pathway between VP/VLBW and poor expiratory airflow. We focused our analyses on VP and VLBW participants combined; however, summary results reported for either VP alone or VLBW alone were almost identical. Finally, we do not have data on expiratory flow across a broad range of adult ages to determine the true longitudinal trajectory of expiratory flows in VP/VLBW survivors into late adulthood, which has occurred in part because so few VP/VLBW participants survived into adulthood before the time of birth of the cohorts included in this study. However, given the clear reductions in airflow in VP/VLBW survivors compared with controls up to the early 30 s in the current study, particularly in those who had BPD, follow-up into later adulthood of our cohorts is mandatory.

What can be done? Given the worse expiratory flow rates among survivors born VP/VLBW who had BPD, we must try to reduce rates of BPD in the newborn period. However, rates of BPD may be increasing and not decreasing in survivors born $<28$ weeks' gestational age in more recent eras, and their expiratory flow rates in childhood may be deteriorating, ${ }^{37}$ which, if true, will only exacerbate the problem of airway obstruction in adulthood in survivors born VP/VLBW from more recent eras. Adult physicians, be they general practitioners or specialists, should be aware that more VP/VLBW infants are surviving into adulthood, and that they are more likely to present with respiratory problems than those born at term, particularly those who had BPD. Physicians should obtain a perinatal history, including birthweight, gestational age and BPD, when assessing adults with airway disease, and be aware that those who were VP/VLBW or who had BPD are likely to be at higher risk of later chronic obstructive pulmonary disease. In the absence of any bronchodilator data to the contrary, it is possible that survivors born VP/VLBW may have fixed airway obstruction that may not respond to any COPD treatment, and therefore therapeutic approaches in VP/VLBW survivors may need to differ from other, e.g., smokingrelated patients with COPD. Notwithstanding the higher zFVC in smokers in the short-term in the current study, avoidance of smoking in the longer-term is paramount to avoiding COPD in later life. 
In conclusion, survivors born VP/VLBW from the era of modern intensive care are not reaching their full airway growth potential in early adulthood: already at that time they were more than four-fold more likely to have clinically important reduced values for airflow than NBW or termborn controls. Those who had BPD in the newborn period are even more disadvantaged. Unless the rate of decline in airflow with age is lower in adult VP/VLBW survivors compared with what normally occurs, many will develop COPD in later adult life.

\section{Author contributions}

LD: conception and design of the study, data collection, analysis and interpretation, drafting and revising the article, and approval of the final manuscript as submitted.

SA: data collection and interpretation, revising the article, and approval of the final manuscript as submitted.

$\mathrm{AB}$ : conception and design of the study, data collection and interpretation, revising the article, and approval of the final manuscript as submitted.

JLYC: conception and design of the study, data analysis and interpretation, drafting and revising the article, and approval of the final manuscript as submitted.

HC: data collection and interpretation, revising the article, and approval of the final manuscript as submitted.

KAnneIE: conception and design of the study, data collection and interpretation, revising the article, and approval of the final manuscript as submitted.

AG: data collection and interpretation, revising the article, and approval of the final manuscript as submitted.

TH: conception and design of the study, data collection and interpretation, revising the article, and approval of the final manuscript ,as submitted.

PH: conception and design of the study, data collection and interpretation, revising the article, and approval of the final manuscript as submitted. 
EK: conception and design of the study, data collection and interpretation, revising the article, and approval of the final manuscript as submitted.

KJL: data analysis and interpretation, revising the article, and approval of the final manuscript as submitted.

LMcG: conception and design of the study, data collection and interpretation, revising the article, and approval of the final manuscript as submitted.

IN: data collection and interpretation, revising the article, and approval of the final manuscript as submitted.

PN-G: data interpretation, revising the article, and approval of the final manuscript as submitted.

SS: data collection and interpretation, revising the article, and approval of the final manuscript as submitted.

MV: conception and design of the study, data collection and interpretation, revising the article, and approval of the final manuscript as submitted.

EJLEV: conception and design of the study, data collection and interpretation, revising the article, and approval of the final manuscript as submitted.

\section{Sources of support}

Grants from the National Health and Medical Research Council of Australia (Program Grant \#606789; Project Grant \#491246; Centre of Clinical Research Excellence \#546519; Centre of Research Excellence \#1060733; Career Development Fellowship \#1141354 to JC and 1127984 to KJL); University of Bergen and Western Norway Regional Authority; National Institute for Health Research, UK, Senior Investigator to AB; de Stichting Astmabestrijding; St. Olav's Hospital's Research Fund; Academy of Finland (grants 127437, 129306, 130326, 134791, 263924, 274794 and 288966), European Commission (H2020 award SC1-2016-RTD-733180 RECAP), Novo Nordisk Foundation, Foundation for Pediatric Research, Foundation for Cardiovascular Research, Foundation for Diabetes Research, Sigrid Juselius Foundation, Signe and Ane Gyllenberg Foundation, Juho Vainio Foundation, and the Yrjö Jahnsson Foundation; NICHD contracts No. 1-HD-4-2803 and No. 1-HD-1-3127; the Victorian Government's 
Operational Infrastructure Support Program. The funding sources had no role in the study design; in the collection, analysis, and interpretation of data; in the writing of the report; or in the decision to submit the paper for publication. 


\section{References}

1. Stocks J, Hislop A, Sonnappa S. Early lung development: lifelong effect on respiratory health and disease. Lancet Respir Med 2013; 1(9): 728-42.

2. Kohansal R, Martinez-Camblor P, Agusti A, Buist AS, Mannino DM, Soriano JB. The natural history of chronic airflow obstruction revisited: an analysis of the Framingham offspring cohort. Am J Respir Crit Care Med 2009; 180(1): 3-10.

3. Blencowe H, Cousens S, Oestergaard MZ, et al. National, regional, and worldwide estimates of preterm birth rates in the year 2010 with time trends since 1990 for selected countries: a systematic analysis and implications. Lancet 2012; 379(9832): 2162-72.

4. Taffel SM. Trends in low birth weight: United States, 1975-85. Vital Health Stat 21 1989; (48): 1-30.

5. Lee KS, Kim BI, Khoshnood B, et al. Outcome of very low birth weight infants in industrialized countries: 1947-1987. Am J Epidemiol 1995; 141(12): 1188-93.

6. Gibson AM, Reddington C, McBride L, Callanan C, Robertson C, Doyle LW. Lung function in adult survivors of very low birth weight, with and without bronchopulmonary dysplasia. Pediatr Pulmonol 2015; 50(10): 987-94.

7. Saarenpaa HK, Tikanmaki M, Sipola-Leppanen M, et al. Lung function in very low birth weight adults. Pediatrics 2015; 136(4): 642-50.

8. Gough A, Linden M, Spence D, Patterson CC, Halliday HL, McGarvey LP. Impaired lung function and health status in adult survivors of bronchopulmonary dysplasia. Eur Respir J 2014; 43(3): 808-16.

9. Narang I, Rosenthal M, Cremonesini D, Silverman M, Bush A. Longitudinal evaluation of airway function 21 years after preterm birth. Am J Respir Crit Care Med 2008; 178(1): 74-80.

10. Vrijlandt EJ, Gerritsen J, Boezen HM, Grevink RG, Duiverman EJ. Lung function and exercise capacity in young adults born prematurely. Am J Respir Crit Care Med 2006; 173(8): 890-6.

11. Vollsaeter M, Roksund OD, Eide GE, Markestad T, Halvorsen T. Lung function after preterm birth: development from mid-childhood to adulthood. Thorax 2013; 68(8): 767-76.

12. Evensen KA, Steinshamn S, Tjonna AE, et al. Effects of preterm birth and fetal growth retardation on cardiovascular risk factors in young adulthood. Early Hum Dev 2009; 85(4): 239-45.

13. Vollsaeter M, Clemm HH, Satrell E, et al. Adult respiratory outcomes of extreme preterm birth. A regional cohort study. Ann Am Thorac Soc 2015; 12(3): 313-22.

14. Doyle LW, Adams AM, Robertson C, et al. Increasing airway obstruction from 8 to 18 years in extremely preterm/low-birthweight survivors born in the surfactant era. Thorax 2017; 72(8): 712-9.

15. Hovi P, Vohr B, Ment LR, et al. Blood pressure in young adults born at very low birth weight: Adults born Preterm International Collaboration. Hypertension 2016; 68(4): 880-7.

16. Cole TJ, Freeman JV, Preece MA. British 1990 growth reference centiles for weight, height, body mass index and head circumference fitted by maximum penalized likelihood. Stat Med 1998; 17(4): 407-29.

17. Northway WH, Jr., Rosan RC, Porter DY. Pulmonary disease following respirator therapy of hyalinemembrane disease. Bronchopulmonary dysplasia. N Engl J Med 1967; 276(7): 357-68.

18. Jobe AH, Bancalari E. Bronchopulmonary dysplasia. Am J Respir Crit Care Med 2001; 163(7): 1723-9.

19. Miller MR, Crapo R, Hankinson J, et al. General considerations for lung function testing. Eur Respir J 2005; 26(1): 153-61.

20. Quanjer PH, Stanojevic S, Cole TJ, et al. Multi-ethnic reference values for spirometry for the 3-95-yr age range: the global lung function 2012 equations. Eur Respir J 2012; 40(6): 1324-43.

21. Stata/IC 15.1 for Windows. College Station, TX: Stata Corp LLC; 2018.

22. Doyle LW, Faber B, Callanan C, Freezer N, Ford GW, Davis NM. Bronchopulmonary dysplasia in very low birth weight subjects and lung function in late adolescence. Pediatrics 2006; 118: 108-13.

23. Halvorsen T, Skadberg BT, Eide GE, Roksund OD, Carlsen KH, Bakke P. Pulmonary outcome in adolescents of extreme preterm birth: a regional cohort study. Acta Paediatr 2004; 93(10): 1294-300.

24. Lange P, Celli B, Agusti A, et al. Lung-function trajectories leading to chronic obstructive pulmonary disease. $N$ Engl J Med 2015; 373(2): 111-22.

25. Halvorsen T, Skadberg BT, Eide GE, Roksund OD, Markestad T. Better care of immature infants; has it influenced long-term pulmonary outcome? Acta Paediatr 2006; 95(5): 547-54.

26. Northway WH, Jr., Moss RB, Carlisle KB, et al. Late pulmonary sequelae of bronchopulmonary dysplasia. $N$ Engl J Med 1990; 323(26): 1793-9. 
27. Wong PM, Lees AN, Louw J, et al. Emphysema in young adult survivors of moderate-to-severe bronchopulmonary dysplasia. Eur Respir J 2008; 32(2): 321-8.

28. Landry JS, Tremblay GM, Li PZ, Wong C, Benedetti A, Taivassalo T. Lung function and bronchial hyperresponsiveness in adults born prematurely. A cohort study. Ann Am Thorac Soc 2016; 13(1): 17-24.

29. Moschino L, Stocchero M, Filippone M, Carraro S, Baraldi E. Longitudinal assessment of lung function in survivors of bronchopulmonary dysplasia from birth to adulthood. The Padova BPD Study. Am J Respir Crit Care Med 2018; 198(1): 134-7.

30. Boezen HM, Vonk JM, van Aalderen WM, et al. Perinatal predictors of respiratory symptoms and lung function at a young adult age. Eur Respir J 2002; 20(2): 383-90.

31. Suresh S, Mamun AA, O'Callaghan M, Sly PD. The impact of birth weight on peak lung function in young adults. Chest 2012; 142(6): 1603-10.

32. Gold DR, Wang X, Wypij D, Speizer FE, Ware JH, Dockery DW. Effects of cigarette smoking on lung function in adolescent boys and girls. $N$ Engl J Med 1996; 335(13): 931-7.

33. Barker DJ, Godfrey KM, Fall C, Osmond C, Winter PD, Shaheen SO. Relation of birth weight and childhood respiratory infection to adult lung function and death from chronic obstructive airways disease. Bmj 1991; 303(6804): 671-5.

34. Brostrom EB, Akre O, Katz-Salamon M, Jaraj D, Kaijser M. Obstructive pulmonary disease in old age among individuals born preterm. Eur J Epidemiol 2013; 28(1): 79-85.

35. Bui DS, Lodge CJ, Burgess JA, et al. Childhood predictors of lung function trajectories and future COPD risk: a prospective cohort study from the first to the sixth decade of life. Lancet Respir Med 2018; 6(7): 535-44.

36. Belgrave DCM, Granell R, Turner SW, et al. Lung function trajectories from pre-school age to adulthood and their associations with early life factors: a retrospective analysis of three population-based birth cohort studies. Lancet Respir Med 2018; 6(7): 526-34.

37. Doyle LW, Carse E, Adams AM, et al. Ventilation in extremely preterm infants and respiratory function at 8 years $N$ Engl J Med 2017; 377(4): 329-37.

38. Vik T, Vatten L, Markestad T, Ahlsten G, Jacobsen G, Bakketeig LS. Morbidity during the first year of life in small for gestational age infants. Arch Dis Child Fetal Neonatal Ed 1996; 75(1): F33-7. 
Table 1. Demographic characteristics of published studies with expiratory flow data reported in late adolescence/early adulthood in VP/VLBW survivors and controls.

\begin{tabular}{|c|c|c|c|c|c|c|c|}
\hline First author & Country & $\begin{array}{l}\text { Data } \\
\text { source }\end{array}$ & $\begin{array}{l}\text { Birth } \\
\text { years }\end{array}$ & $\begin{array}{l}\text { Eligibility } \\
\text { criteria* }\end{array}$ & $\begin{array}{c}\text { Mean } \\
\text { age } \\
\text { (range) } \\
\text { (years)* }\end{array}$ & $\begin{array}{c}\text { VP/VLBW } \\
\mathbf{N}=\end{array}$ & $\begin{array}{c}\text { Control } \\
\mathbf{N}=\end{array}$ \\
\hline Doyle $^{22}$ & Australia & hospital & $\begin{array}{l}1977- \\
82\end{array}$ & $<1501 \mathrm{~g}$ & $\begin{array}{c}19(18- \\
22)\end{array}$ & 146 & 37 \\
\hline Gibson $^{6}$ & Australia & hospital & $\begin{array}{l}1977- \\
82\end{array}$ & $<1501 \mathrm{~g}$ & $\begin{array}{c}26(24- \\
29)\end{array}$ & 87 & 19 \\
\hline Saarenpaa $^{7}$ & Finland & hospital $\uparrow$ & $\begin{array}{l}1978- \\
85\end{array}$ & $<1501 \mathrm{~g}$ & $\begin{array}{c}22(18- \\
27)\end{array}$ & 160 & 162 \\
\hline Gough $^{8}$ & N. Ireland & hospital & $\begin{array}{l}1978- \\
93\end{array}$ & $\begin{array}{l}\text { BPD and } \\
<1500 \mathrm{~g}\end{array}$ & $\begin{array}{c}26(18- \\
33)\end{array}$ & 100 & 78 \\
\hline Narang $^{9}$ & England & hospital & $\begin{array}{l}1979- \\
80\end{array}$ & $\begin{array}{l}<2000 \mathrm{~g} / \\
<37 \mathrm{w}\end{array}$ & $\begin{array}{c}22(19- \\
25)\end{array}$ & 38 & 48 \\
\hline Vrijlandt ${ }^{10}$ & $\begin{array}{l}\text { The } \\
\text { Netherlands }\end{array}$ & $\begin{array}{l}\text { two } \\
\text { hospitals }\end{array}$ & 1983 & $\begin{array}{c}<1500 \\
\mathrm{~g} /<32 \mathrm{~W}\end{array}$ & $\begin{array}{c}20(19- \\
21)\end{array}$ & 41 & 53 \\
\hline Halvorsen ${ }^{11,13,23}$ & Norway & regional & $\begin{array}{l}1982- \\
85\end{array}$ & $\begin{array}{c}<1001 \\
\mathrm{~g} /<29 \mathrm{w}\end{array}$ & $\begin{array}{c}18(16- \\
20)\end{array}$ & 41 & 42 \\
\hline Vollsaeter $^{11,13}$ & Norway & regional & $\begin{array}{l}1982- \\
85\end{array}$ & $\begin{array}{c}<1001 \\
\mathrm{~g} /<29 \mathrm{~W}\end{array}$ & $\begin{array}{c}25(24- \\
26)\end{array}$ & 45 & 39 \\
\hline Evensen $^{12}$ & Norway & regional & $\begin{array}{l}1986- \\
88\end{array}$ & $<1501 \mathrm{~g}$ & $\begin{array}{c}18(17- \\
19)\end{array}$ & 38 & 63 \\
\hline Vollsaeter ${ }^{13}$ & Norway & regional & $\begin{array}{l}1991- \\
92\end{array}$ & $\begin{array}{c}<1001 \\
\mathrm{~g} /<29 \mathrm{w}\end{array}$ & $\begin{array}{c}19(17- \\
20)\end{array}$ & 31 & 28 \\
\hline Doyle $^{14}$ & Australia & regional & $\begin{array}{l}1991- \\
92\end{array}$ & $\begin{array}{c}<1000 \\
\mathrm{~g} /<28 \mathrm{w}\end{array}$ & $\begin{array}{c}18(16- \\
20)\end{array}$ & 208 & 153 \\
\hline
\end{tabular}


*criteria for inclusion in original study; the numbers in this table relate only to those VP/VLBW or controls; $\uparrow$ the only tertiary hospital within a geographical region

$\mathrm{VP}=$ =very preterm; $\mathrm{VLBW}=$ very low birth weight; $\mathrm{BW}=$ birthweight; $\mathrm{GA}=$ gestational age;

$\mathrm{BPD}=$ bronchopulmonary dysplasia; $\mathrm{w}=$ weeks 
Table 2. Clinical characteristics of very preterm/very low birthweight participants by cohort.

\begin{tabular}{|c|c|c|c|c|c|c|c|c|c|}
\hline Study & $\mathbf{N}$ & $\begin{array}{l}\text { Antenatal } \\
\text { cortico- } \\
\text { steroids } \\
\text { - \% (n) }\end{array}$ & $\begin{array}{l}\text { Gestation } \\
\text { (weeks) }\end{array}$ & $\begin{array}{l}\text { Birth } \\
\text { weight } \\
\text { (g) }\end{array}$ & $\begin{array}{l}\text { Birth } \\
\text { weight } \\
\text { z-score }\end{array}$ & $\begin{array}{l}\text { Male } \\
-\% \\
\text { (n) }\end{array}$ & $\begin{array}{l}\text { Surfactant } \\
-\% \text { (n) }\end{array}$ & $\begin{array}{l}\text { BPD } \\
-\% \\
\text { (n) }\end{array}$ & $\begin{array}{l}\text { Smoking } \\
-\% \text { (n) }\end{array}$ \\
\hline Doyle $^{22}$ & 146 & $53 \%(77)$ & $28.8(2.0)$ & $\begin{array}{l}1095 \\
(234)\end{array}$ & $\begin{array}{l}-0.73 \\
(1.00)\end{array}$ & $\begin{array}{l}48 \% \\
(70)\end{array}$ & $0 \%(0)$ & $\begin{array}{l}23 \% * \\
(33)\end{array}$ & $34 \%(49)$ \\
\hline Gibson $^{6}$ & 87 & $53 \%(46)$ & $28.4(1.9)$ & $\begin{array}{l}1035 \\
(212)\end{array}$ & $\begin{array}{l}-0.78 \\
(1.02)\end{array}$ & $\begin{array}{l}44 \% \\
(38)\end{array}$ & $0 \%(0)$ & $\begin{array}{l}28 \% * \\
(24)\end{array}$ & $32 \%(28)$ \\
\hline $\begin{array}{l}\text { Saarenpaa } \\
7\end{array}$ & 160 & $6 \%(10)$ & $29.2(2.2)$ & $\begin{array}{l}1126 \\
(218)\end{array}$ & $\begin{array}{l}-0.80 \\
(1.11)\end{array}$ & $\begin{array}{l}42 \% \\
(68)\end{array}$ & $4 \%(7)$ & $\begin{array}{l}18 \% * \\
(29)\end{array}$ & $38 \%(60)$ \\
\hline Gough $^{8}$ & 100 & $31 \%(31)$ & $28.9(2.9)$ & $\begin{array}{l}1078 \\
(280)\end{array}$ & $\begin{array}{l}-0.92 \\
(1.20)\end{array}$ & $\begin{array}{l}47 \% \\
(47)\end{array}$ & $\begin{array}{l}31 \% \\
(18 / 58) \S\end{array}$ & $\begin{array}{l}58 \% \dagger \\
(58)\end{array}$ & $16 \%(16)$ \\
\hline Narang $^{9}$ & 38 & $29 \%(11)$ & $30.1(2.4)$ & $\begin{array}{l}1250 \\
(239)\end{array}$ & $\begin{array}{l}-0.86 \\
(1.31)\end{array}$ & $\begin{array}{l}63 \% \\
(24)\end{array}$ & $0 \%(0)$ & $\begin{array}{l}18 \% * \\
(7)\end{array}$ & $39 \%(15)$ \\
\hline${ }_{0}$ Vrijlandt $^{1}$ & 41 & $10 \%(4)$ & $29.9(2.5)$ & $\begin{array}{l}1247 \\
(232)\end{array}$ & $\begin{array}{l}-0.66 \\
(1.58)\end{array}$ & $\begin{array}{l}51 \% \\
(21)\end{array}$ & $0 \%(0)$ & $\begin{array}{l}22 \% * \\
(9)\end{array}$ & $32 \%(13)$ \\
\hline $\begin{array}{l}\text { Halvorsen } \\
23\end{array}$ & 41 & $29 \%(12)$ & $27.3(1.5)$ & $\begin{array}{l}1035 \\
(185)\end{array}$ & $\begin{array}{l}-0.05 \\
(1.05)\end{array}$ & $\begin{array}{l}54 \% \\
(22)\end{array}$ & $0 \%(0)$ & $\begin{array}{l}76 \% \dagger \\
(31)\end{array}$ & $37 \%(15)$ \\
\hline $\begin{array}{l}\text { Vollsaeter } \\
11,13\end{array}$ & 45 & $36 \%(16)$ & $27.4(1.5)$ & $\begin{array}{l}1006 \\
(193)\end{array}$ & $\begin{array}{l}-0.27 \\
(1.16)\end{array}$ & $\begin{array}{l}58 \% \\
(26)\end{array}$ & $0 \%(0)$ & $\begin{array}{l}76 \% \dagger \\
(34)\end{array}$ & $31 \%(14)$ \\
\hline Evensen $^{12}$ & 38 & $55 \%(21)$ & $29.2(2.5)$ & $\begin{array}{l}1242 \\
(203)\end{array}$ & $\begin{array}{l}-0.26 \\
(1.27)\end{array}$ & $\begin{array}{l}53 \% \\
(20)\end{array}$ & $0 \%(0)$ & $\begin{array}{l}18 \% \dagger \\
(7)\end{array}$ & $\begin{array}{l}31 \% \\
(11 / 36)\end{array}$ \\
\hline $\begin{array}{l}\text { Vollsaeter } \\
13\end{array}$ & 31 & $39 \%(12)$ & $26.8(1.8)$ & $\begin{array}{l}942 \\
(209)\end{array}$ & $\begin{array}{l}-0.21 \\
(1.06)\end{array}$ & $\begin{array}{l}42 \% \\
(13)\end{array}$ & $52 \%(16)$ & $\begin{array}{l}77 \% \dagger \\
(24)\end{array}$ & $3(1)$ \\
\hline Doyle $^{14}$ & 208 & $71 \%(148)$ & $26.7(2.0)$ & $\begin{array}{l}889 \\
162)\end{array}$ & $\begin{array}{l}-0.35 \\
(1.33)\end{array}$ & $\begin{array}{l}45 \% \\
(93)\end{array}$ & $40 \%(83)$ & $\begin{array}{l}37 \% \\
(77)\end{array}$ & $21 \%(43)$ \\
\hline Overall & 935 & $41 \%(388)$ & $28.3(2.4)$ & $\begin{array}{l}1054 \\
(241)\end{array}$ & $\begin{array}{l}-0.59 \\
(1.21)\end{array}$ & $\begin{array}{l}47 \% \\
(442)\end{array}$ & $\begin{array}{l}15 \% \\
(124 / 855)\end{array}$ & $\begin{array}{l}36 \% \\
(333)\end{array}$ & $\begin{array}{l}28 \% \\
(265)\end{array}$ \\
\hline
\end{tabular}

Data are mean (SD), unless otherwise specified. BPD=bronchopulmonary dysplasia. 
*BPD determined by oxygen requirement $>28$ days and chest X-ray consistent with Northway Stage 3 or 4 changes. ${ }^{17} \dagger$ BPD determined by oxygen requirement $>28$ days $\ddagger$ BPD determined by oxygen dependency at 36 weeks' postmenstrual age; §reported for BPD subgroup only 
Table 3. Expiratory flow variables contrasted between VP/VLBW and control groups.

\begin{tabular}{|c|c|c|c|c|}
\hline Expiratory & VP/VLBW & Controls & & \\
\hline flow & $\mathrm{N}=935$ & $\mathrm{~N}=722$ & & \\
\hline & Mean (SD) & Mean (SD) & Mean difference $(95 \% \mathrm{CI}) *$ & P-value* \\
\hline $\mathrm{zFEV}_{1}$ & $-0.81(1.33)$ & $-0.06(1.03)$ & $-0.78(-0.96,-0.61)$ & $<0.0001$ \\
\hline zFVC & $-0.38(1.18)$ & $-0.15(0.98)$ & $-0.25(-0.40,-0.10)$ & 0.001 \\
\hline $\mathrm{zFEV}_{1} / \mathrm{FVC}$ & $-0.64(1.35)$ & $0.14(1.10)$ & $-0.74(-0.85,-0.64)$ & $<0.0001$ \\
\hline \multirow[t]{2}{*}{$\mathrm{zFEF}_{25-75 \%}$} & $-0.95(1.47) \mathrm{N}=851$ & $-0.04(1.10) \mathrm{N}=606$ & $-0.88(-1.12,-0.65)$ & $<0.0001$ \\
\hline & $\%<5^{\text {th }}$ centile $(\mathrm{n})$ & $\%<5^{\text {th }}$ centile $(\mathrm{n})$ & Odds ratio $(95 \% \mathrm{CI})^{*}$ & P-value* \\
\hline $\mathrm{FEV}_{1}$ & $24 \%(221)$ & $7 \%(50)$ & $4.16(2.99,5.78)$ & $<0.0001$ \\
\hline FVC & $11 \%(100)$ & $6 \%(42)$ & $2.12(1.44,3.14)$ & $<0.0001$ \\
\hline $\mathrm{FEV}_{1} / \mathrm{FVC}$ & $23 \%(213)$ & $6 \%(40)$ & $5.09(3.54,7.30)$ & $<0.0001$ \\
\hline $\mathrm{FEF}_{25-75 \%}$ & $29 \%(247 / 851)$ & $8 \%(46 / 606)$ & $4.50(2.82,7.19)$ & $<0.0001$ \\
\hline
\end{tabular}

*from individual participant data meta-analysis.

$\mathrm{VP}=$ very preterm; $\mathrm{VLBW}=$ very low birth weight; $\mathrm{CI}=$ confidence interval; $\mathrm{SD}=$ standard deviation; $\mathrm{FEV}_{1}=$ forced expired volume in 1 second; $\mathrm{FVC}=$ forced vital capacity; $\mathrm{FEF}_{25-75 \%=\text { flow }}$ between $25 \%-75 \%$ of the vital capacity. 
Table 4. Changes in z-scores for expiratory flows between 18 and 25 years in the subset of participants with values at both ages, contrasted between VP/VLBW and control groups.

\begin{tabular}{|c|c|c|c|c|c|c|}
\hline \multirow{4}{*}{$\begin{array}{l}\text { Expiratory } \\
\text { flow }\end{array}$} & VP/VLBW & Controls & & & & \multirow{4}{*}{$\begin{array}{c}\text { P- } \\
\text { value }\end{array}$} \\
\hline & $\mathrm{N}=117$ & $\mathrm{~N}=53$ & & & & \\
\hline & \multirow[t]{2}{*}{$\begin{array}{c}\text { Mean } \\
\text { change (SD) }\end{array}$} & \multirow[t]{2}{*}{$\begin{array}{c}\text { Mean } \\
\text { change } \\
\text { (SD) }\end{array}$} & $\begin{array}{c}\text { Mean } \\
\text { difference in } \\
\text { change* }(95 \%\end{array}$ & $\begin{array}{c}\text { P- } \\
\text { value }\end{array}$ & $\begin{array}{l}\text { Adjusted mean } \\
\text { difference in } \\
\text { change*† }(95 \%\end{array}$ & \\
\hline & & & $\mathrm{CI})$ & & $\mathrm{CI})$ & \\
\hline \multirow[t]{2}{*}{$\mathrm{zFEV}_{1}$} & \multirow[t]{2}{*}{$0.14(0.67)$} & 0.20 & $-0.07(-0.25$ & 0.48 & $-0.16(-0.37$ & 0.16 \\
\hline & & $(0.51)$ & $0.12)$ & & $0.06)$ & \\
\hline \multirow[t]{2}{*}{$\mathrm{zFVC}$} & \multirow[t]{2}{*}{$0.20(0.75)$} & 0.46 & $-0.26(-0.46,-$ & 0.007 & $-0.32(-0.52,-$ & 0.002 \\
\hline & & $(0.51)$ & $0.07)$ & & $0.11)$ & \\
\hline \multirow[t]{2}{*}{$\mathrm{zFEV}_{1} / \mathrm{FVC}$} & \multirow[t]{2}{*}{$-0.11(0.77)$} & -0.43 & $0.32(0.07$ & 0.011 & $0.02(-0.23,0.27)$ & 0.90 \\
\hline & & $(0.77)$ & $0.57)$ & & & \\
\hline \multirow[t]{2}{*}{$\mathrm{zFEF}_{25-75 \%}$} & $0.01(0.72)$ & -0.09 & $0.10(-0.13$ & 0.39 & $-0.15(-0.40$ & 0.24 \\
\hline & $\mathrm{N}=114$ & $(0.70)$ & $0.33)$ & & $0.10)$ & \\
\hline
\end{tabular}

* from individual participant data meta-analysis †adjusted for baseline value for expiratory flow

$\mathrm{SD}=$ standard deviation; $\mathrm{CI}=$ confidence interval; $\mathrm{FEV}_{1}=$ forced expired volume in 1 second; $\mathrm{FVC}=$ forced vital capacity; $\mathrm{FEF}_{25-75 \%}=$ flow between $25 \%-75 \%$ of the vital capacity. 
Figure 1. Associations of expiratory flows (z-scores) with perinatal and demographic variables among VP/VLBW participants. Mean differences and 95\% confidence intervals for unit change in independent variable (except for Year of birth and Age - per 5 years). Solid line $=$ univariable analyses; dashed line $=$ multivariable analyses.

$\mathrm{CS}=$ corticosteroids; $\mathrm{BPD}=$ bronchopulmonary dysplasia; $\mathrm{SD}=$ standard deviation; $\mathrm{FEV}_{1}=$ forced expired volume in 1 second; $\mathrm{FVC}=$ forced vital capacity; $\mathrm{FEF}_{25-75 \%}=$ flow between $25 \%-75 \%$ of the vital capacity.

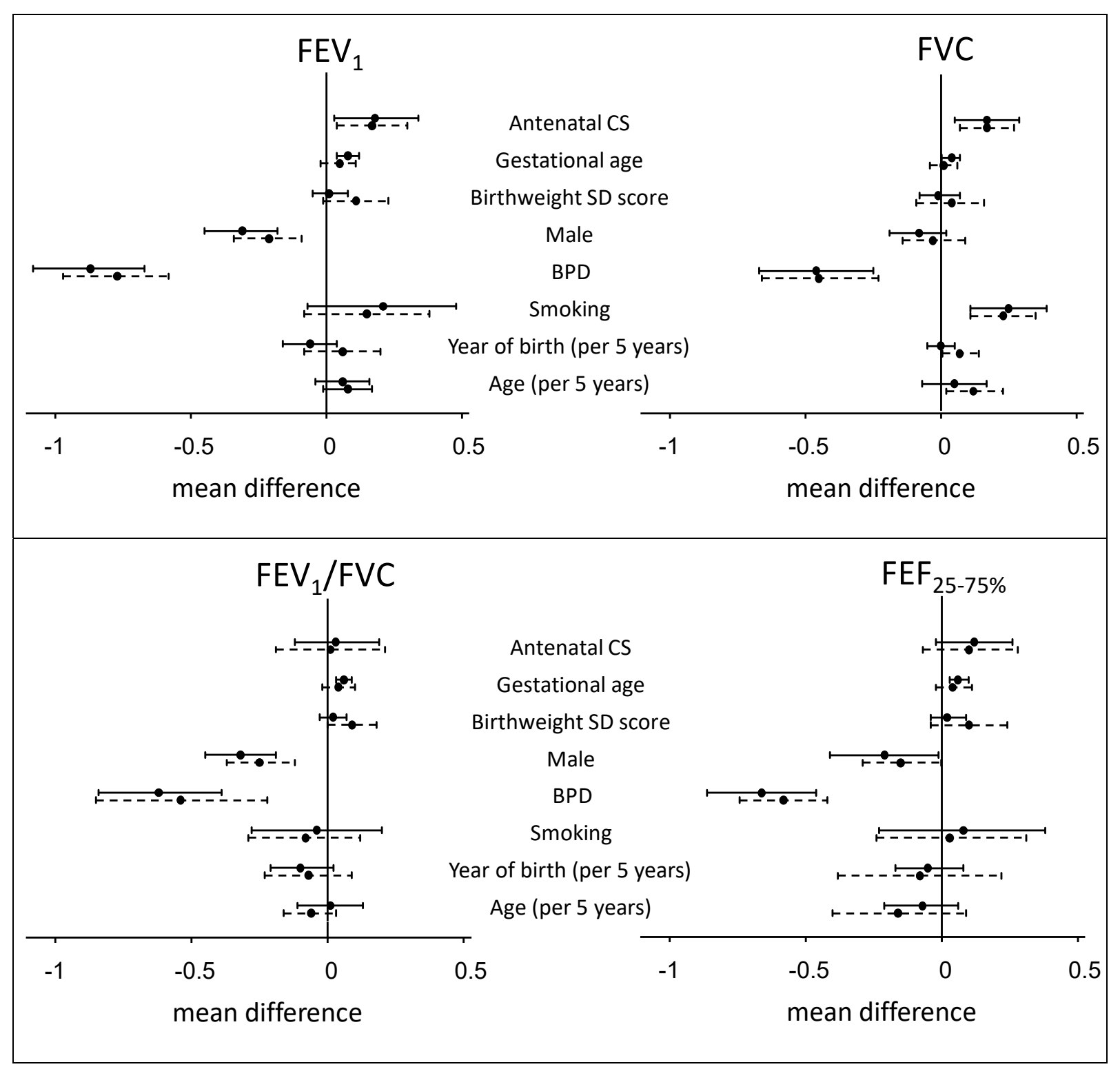


Supplementary Table 1. Selection criteria for control groups.

\begin{tabular}{|c|c|c|c|c|}
\hline First author & Eligibility criteria* & $\begin{array}{l}\mathrm{N} \text { in } \\
\text { initial } \\
\text { cohort }\end{array}$ & $\begin{array}{l}\text { Birth } \\
\text { weight } \\
(\mathrm{g})^{*}\end{array}$ & $\begin{array}{l}\text { Gestational } \\
\text { age } \\
(\text { weeks)* }\end{array}$ \\
\hline Doyle $^{22}$ & $\begin{array}{l}\text { Randomly selected from births with } \\
\text { birthweights }>2499 \mathrm{~g} \text { within the Royal } \\
\text { Women's Hospital, Melbourne born } \\
\text { between October } 1981 \text { and March } 1992\end{array}$ & 60 & $\begin{array}{l}3505 \\
(496)\end{array}$ & $39.9(1.2)$ \\
\hline Gibson $^{6}$ & Same cohort as for Doyle ${ }^{22}$ & 60 & $\begin{array}{l}3535 \\
(462)\end{array}$ & $40.2(0.8)$ \\
\hline Saarenpaa $^{7}$ & $\begin{array}{l}\text { The next infant following the birth of a } \\
\text { VLBW participant of the same sex who } \\
\text { was born at term and with birth weight SD } \\
\text { score } \geq-2.0 ; 314 \text { control subjects living in } \\
\text { greater Helsinki were invited to participate } \\
\text { and, } 172(54.8 \%) \text { accepted }\end{array}$ & 172 & $\begin{array}{l}3599 \\
(466)\end{array}$ & $40.1(1.1)$ \\
\hline Gough $^{8}$ & $\begin{array}{l}\text { Sex- and birth date-matched (within } 2 \\
\text { weeks of the index group) full-term } \\
\text { individuals, born in the same hospital and } \\
\text { without evidence of respiratory difficulties } \\
\text { during the newborn hospital stay; } 492 \\
\text { potential controls were identified and } \\
\text { traced from hospital records and } 370 \text { were } \\
\text { approached via their general practitioner, } \\
\text { of whom } 84 \text { consented. }\end{array}$ & 84 & $\begin{array}{l}3523 \\
(370)\end{array}$ & $39.6(1.2)$ \\
\hline Narang ${ }^{9}$ & $\begin{array}{l}\text { Control were selected in adulthood who } \\
\text { were }<26 \text { years of age, had a birthweight } \\
>2000 \mathrm{~g} \text {, and gestational age } \geq 37 \text { weeks, } \\
\text { and were free of chronic respiratory }\end{array}$ & 50 & $\begin{array}{l}3520 \\
(583)\end{array}$ & $39.9(1.4)$ \\
\hline
\end{tabular}


disease, cardiac disease, joint disease, or neuromuscular disease Controls were recruited initially from friends of the study group (each index study group subject, at the time of initial contact, was asked to bring a friend of similar age and sex to participate as a control subject), students from the local university, health staff working in the hospital, and friends of colleagues.

\begin{tabular}{|c|c|c|c|c|}
\hline Vrijlandt $^{10}$ & $\begin{array}{l}\text { Preterm participants were asked to bring a } \\
\text { healthy friend to participate in the present } \\
\text { study as an age-matched control subject. } \\
\text { For participants unable to bring a friend, } \\
\text { age-matched medical students were } \\
\text { recruited. Controls had birthweights } \\
>2499 \mathrm{~g} \text {. }\end{array}$ & 53 & $\begin{array}{l}3684 \\
(397)\end{array}$ & $39.6(1.6$ \\
\hline Halvorsen ${ }^{11,13,23}$ & $\begin{array}{l}\text { For each preterm participant the } \\
\text { temporally nearest term-born subject } \\
\text { within the same geographical region of the } \\
\text { same sex with a birthweight between 3-4 } \\
\text { kg was selected as a control }\end{array}$ & 46 & NA & NA \\
\hline Vollsaeter ${ }^{11,13}$ & Same cohort as for Halvorsen ${ }^{11,13,23}$ & 46 & NA & NA \\
\hline Evensen $^{12}$ & $\begin{array}{l}\text { Controls comprised } 63 \text { young adults ( } 29 \\
\text { males, } 34 \text { females) from } 90 \text { invited who } \\
\text { were born at term with normal birth } \\
\text { weight (equal to or above the } 10 \text { th centile) } \\
\text { from a population-based study on causes } \\
\text { and consequences of intrauterine growth } \\
\text { retardation, }{ }^{38} \text { where a } 10 \% \text { random sample }\end{array}$ & 63 & $\begin{array}{l}3718 \\
(443)\end{array}$ & $39.8(1.2$ \\
\hline
\end{tabular}




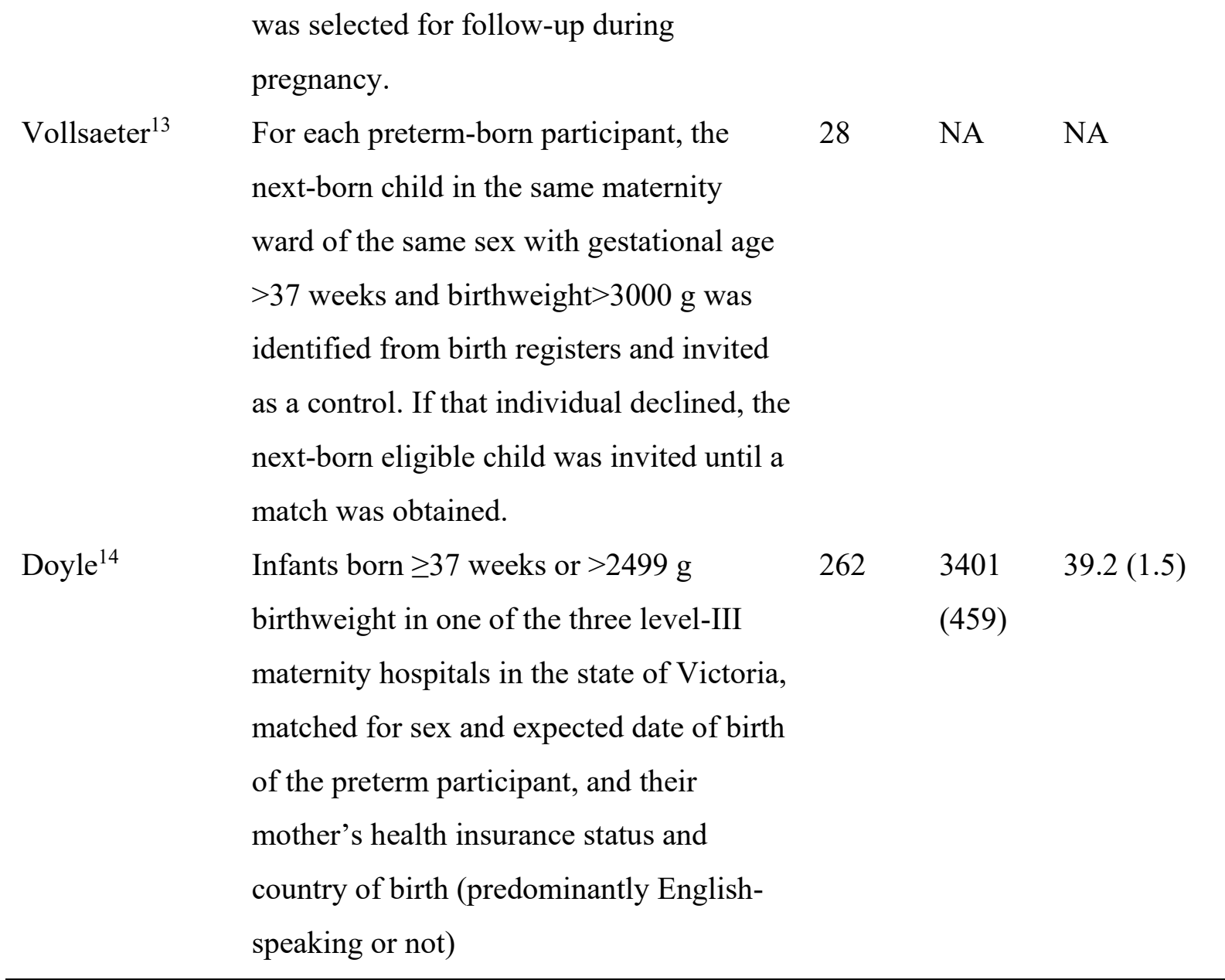

Data are mean (SD), unless otherwise specified

$\mathrm{NA}=$ not available

* in those with expiratory flow data 
Supplementary Table 2. Expiratory flow variables in VP/VLBW, VP only and VLBW only groups.

\begin{tabular}{|c|c|c|c|}
\hline Expiratory flow & $\begin{array}{c}\text { VP/VLBW } \\
\mathrm{N}=935\end{array}$ & $\begin{array}{l}\text { VP only } \\
\mathrm{N}=841\end{array}$ & $\begin{array}{c}\text { VLBW only } \\
\mathrm{N}=927\end{array}$ \\
\hline & Mean (SD) & Mean (SD) & Mean (SD) \\
\hline $\mathrm{zFEV}_{1}$ & $-0.81(1.33)$ & $-0.84(1.33)$ & $-0.82(1.32)$ \\
\hline zFVC & $-0.38(1.18)$ & $-0.39(1.17)$ & $-0.38(1.17)$ \\
\hline $\mathrm{zFEV}_{1} / \mathrm{FVC}$ & $-0.64(1.35)$ & $-0.66(1.37)$ & $-0.65(1.35)$ \\
\hline \multirow[t]{2}{*}{$\mathrm{zFEF}_{25-75 \%}$} & $-0.95(1.47) \mathrm{N}=851$ & $-0.96(1.48) \mathrm{N}=771$ & $-0.95(1.47) \mathrm{N}=849$ \\
\hline & $\%<5^{\text {th }}$ centile $(\mathrm{n})$ & $\%<5^{\text {th }}$ centile $(\mathrm{n})$ & $\%<5^{\text {th }}$ centile $(\mathrm{n})$ \\
\hline $\mathrm{FEV}_{1}$ & $24 \%(221)$ & $24 \%(205)$ & $24 \%(221)$ \\
\hline FVC & $11 \%(100)$ & $10 \%(87)$ & $11 \%(99)$ \\
\hline $\mathrm{FEV}_{1} / \mathrm{FVC}$ & $23 \%(213)$ & $24 \%(202)$ & $23 \%(212)$ \\
\hline $\mathrm{FEF}_{25-75 \%}$ & $29 \%(247 / 851)$ & $30 \%(228 / 771)$ & $29 \%(246 / 849)$ \\
\hline
\end{tabular}

$\mathrm{VP}=$ very preterm; $\mathrm{VLBW}=$ very low birth weight; $\mathrm{SD}=$ standard deviation; $\mathrm{FEV}_{1}=$ forced expired volume in 1 second; $\mathrm{FVC}=$ forced vital capacity; $\mathrm{FEF}_{25-75 \%}=$ flow between $25 \%-75 \%$ of the vital capacity. 
Supplementary Figure 1. Forest plot of mean differences in expiratory flows between VP/VLBW groups and controls for individual studies, with overall estimate of heterogeneity $\left(\mathrm{I}^{2}\right)$.

$\mathrm{CI}=$ confidence interval; $\mathrm{FEV}_{1}=$ forced expired volume in 1 second $\mathrm{FVC}=$ forced vital capacity; $\mathrm{FEF}_{25-75 \%}=$ flow between $25 \%-75 \%$ of the vital capacity

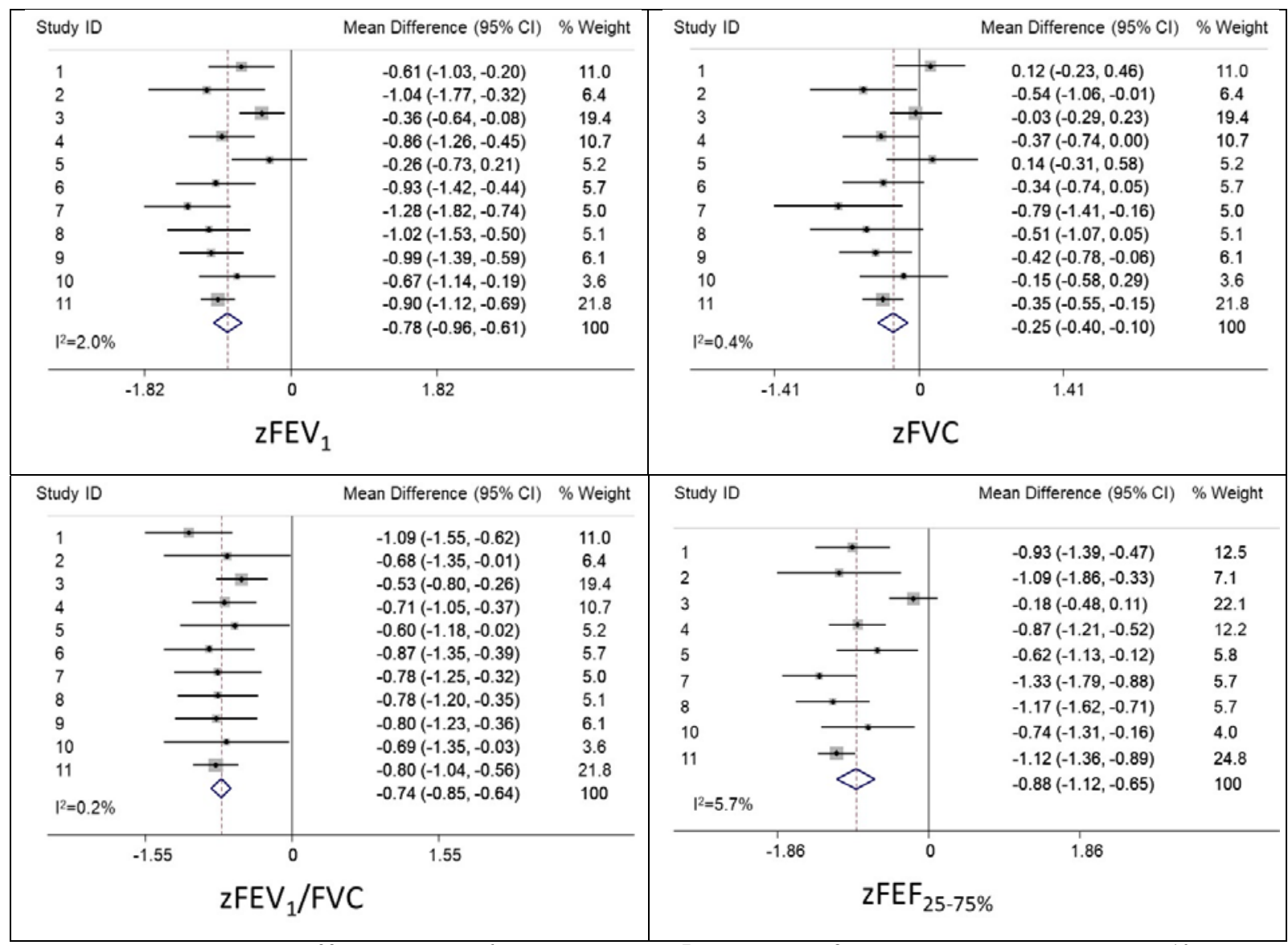

Study number $1=$ Doyle $^{22} ; 2=$ Gibson $^{6} ; 3=$ Saarenpaa $^{7} ; 4=$ Gough $^{8} ; 5=$ Narang $^{9} ; 6=$ Vrijlandt $^{10}$; $7=$ Halvorsen $^{11,13,23} ; 8=$ Vollsaeter $^{11,13} ; 9=$ Evensen $^{12} ; 10=$ Vollsaeter $^{13} ; 11=$ Doyle $^{14}$. 